\title{
Teaching Support System for Competences Development in an Era of Constant Disruption
}

\author{
Riccardo Bonazzi \\ University of Applied Sciences and Arts Western Switzerland, Switzerland \\ Antoine Perruchoud \\ University of Applied Sciences and Arts Western Switzerland, Switzerland
}

\section{Abstract}

In this paper, we present a software to support educators by collecting and processing data in each step of the experimental learning cycle for cognitive apprenticeship. We do so by developing a system that allows educators to (1) define a set of competences, (2) link keywords to each competences, (3) analyse reflexive papers written by students as evidences of their acquired competences after practical projects and (4) analyse multiple documents to assign students to different clusters to better coach them. The theoretical ground for our artefact lays in the intersection between the body of knowledge concerning experiential learning and statistical learning theory. We support our claims by illustrating results coming from 15 students of a Team Academy course and 100 students of a university course.

Keywords: apprenticeship, experiential learning, design science, team academy JEL classification: 123

\section{Introduction}

This paper is mainly addressed to trainers, who looking for new tools to mentor, coach and assess students /employees in their learning journey. We do so, by extending the approach initially developed by the team academy, a model of teaching in which teams of learners create and operate real enterprises which the learners themselves own and control (Tosey, Dhaliwal, \& Hassinen, 2015).

Previous studies have already analysed the positive effects of the Team Academy model, and how it can be adapted to different teaching systems in Europe.

In this paper, we define cognitive apprenticeship as the application of features associated to apprenticeship for the teaching and learning of subjects such as reading, writing, and mathematics (Collins, Brown, \& Newman, 1988, p. 5): (a) conceptual and factual knowledge is exemplified and situated in the contexts of its use; (b) the focus of the learning-through-guided-experience is on cognitive and metacognitive, rather than on physical, skills and processes.

Hence, apprenticeship is a system of training a new generation of practitioners of a profession with on-the-job training and some accompanying study (classroom work and reading). With respect to internship, apprenticeship is more structured and it requires a close collaboration between the firm and teaching professors. In order to structure the apprenticeship process, we propose using the four stages of experiential learning (Kolb, 2014), as shown in Figure 1: (a) Concrete experience, (b) reflective observation, (c) Abstract conceptualization and (d) Active experimentation. 
Figure 1

The Four Roles of the Educator in Experiential Learning

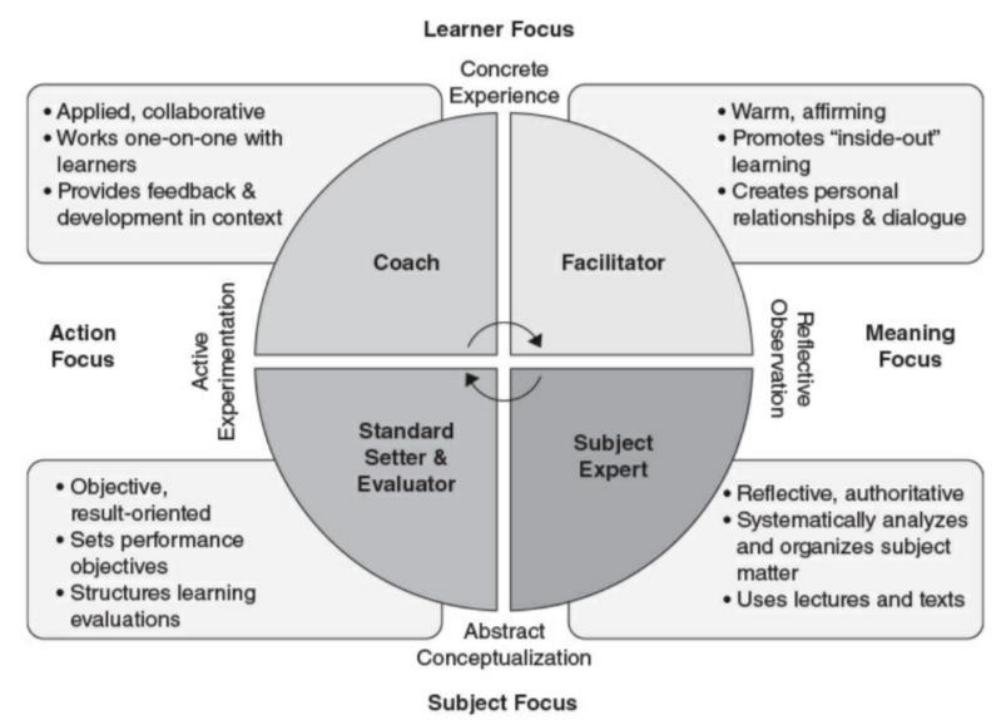

Source: Kolb (2014)

In each step, the role of the educator changes and, although a set of tools exist to support the educator in each step of the cycle, a single tool that gathers data of each step in one single database appears to be missing. Therefore, our research question is "how to support educators collect and process data in each step of the experimental learning cycle for cognitive apprenticeship?"

The rest of the paper proceeds as it follows. Section 2 briefly review the relevant body of knowledge that we will use to answer our research question. Section 3 describes how we create a tool to solve our problem, whereas section 4 illustrates our prototypes. Section 5 concludes the paper by discussing its limitation and by suggesting new directions of investigation.

\section{Literature review}

In this section, we briefly review papers concerning (a) Team Academy as a form of cognitive apprenticeship, (b) the experiential learning cycle and existing techniques to store and analyse data across the steps of the learning cycle.

The Finnish model of education to teach entrepreneurship, called "Team Academy" has already influenced the way management courses are taught in many applied universities across Europe (Tosey et al., 2015). Although it is often presented as a new way of teaching, it might be safe to say that the Team Academy model uses a set of existing approaches in a new way more oriented towards apprenticeship (Lehtonen, 2010):

- The flipped classroom approach is the main format used in this form of teaching, since students are expected to learn most of the notions by themselves and discuss about it during the team training sessions (dialogue with the team for 4 hours, 2 times per week).

- Pedagogical contracts are set every semester by the students, instead of being defined by the teachers of each class.

- Mastery-based learning is achieved by assessing students against 21 competences (leadership, marketing, international skills ... etc) each semester on a range of 1 to 5 . 
- Problem-based learning comes from the written reports (so-called pre/postMotorola) concerning projects that students have to conduct in teams, which can by anything ranging from event organization to creating a new firm selling t-shirts.

- Reflexive learning is often done during the coaching sessions every week, and each student is asked to write reflexive papers on what he/she has read and share teaching lessons after every project

Although many papers have already assessed the Team Academy model, there seems to be a gap in the literature concerning one of the weak spots of the Team Academy approach: the formal assessment of students. Indeed, there are two intrinsic challenges in the way team academy students advance: they produce a large set of documents and each student advance in her own unique way. Accordingly, it is complicated to assess two students in the same way.

To address these issues, figure 2 recalls the four steps of experiential learning and the roles of the educator (Kolb, 2014).

(1) Role 1-Facilitator: It would be possible to imagine that at the beginning of each semester the educators recalls to students the 21 core competences, (Marketing, Leadership, Negotiation ... etc) in order to set their learning contracts. The output of this step can be stored as a list of competences that each student aims at acquiring.

(2) Role 2 - Subject expert: Educators should help students linking keywords with competences. Previous studies has shown that concept maps (Novak, 1990) can be useful for this task (Kinchin et al., 2000). In figure 2, we represent a concept map under the shape of a dictionary, which links every keyword (W) to a competence (C).

(3) Role 3 - Evaluator: scholars of the problem-based learning approach have already suggested evaluators should assess arguments of students claiming to have competences and treat each document (D) is evidence of an acquired competence (C) (Gijbels et al., 2005). In figure 2, we represent every claim as a collection of keywords (W).

(4) Role 4-Coach: In the end, a system that gathers all the evidences produced by the student could allow to assign students into clusters. Among clustering algorithms (James et al., 2013), we are going to focus here on those that use a dependent variable to train their system, and we shall focus on one called decision tree, to extract a simple set of classification rules. 
Figure 2

Alignment Between (A) Role of the Coach in the Team Academy Model, (B) Steps of the Experiential Learning Model and (C) Existing Tools.
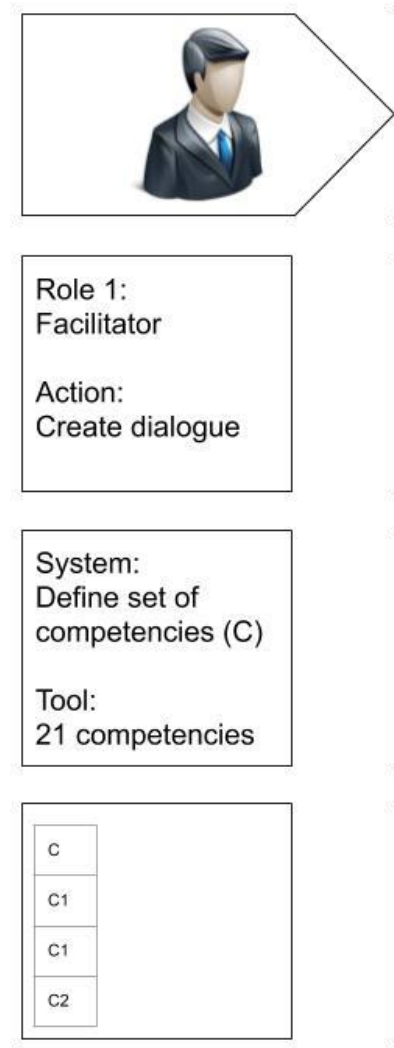

Source: Kolb (2014)

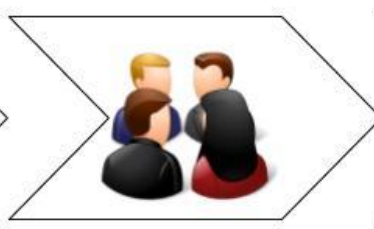

$$
\begin{aligned}
& \text { Role 2: } \\
& \text { Subject Expert } \\
& \text { Action: } \\
& \text { Organize subject } \\
& \text { matters }
\end{aligned}
$$

\section{System}

Associate Words

(W) to (C)

Tool:

Dictionary

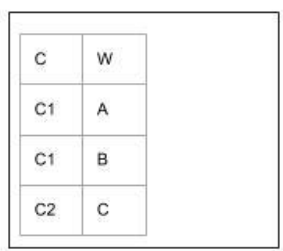

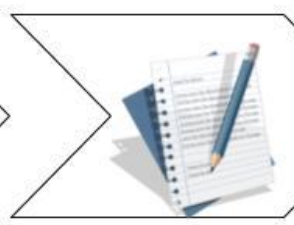

Role 3:

Evaluator

Action:

Structure learning evaluations

System:

Link Documents

(D) to W

Tool:

Text analysis

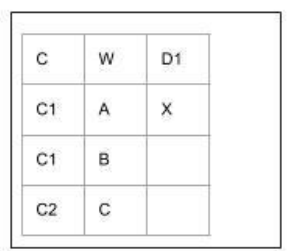

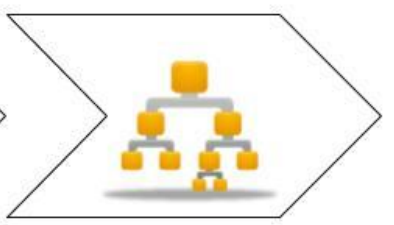

Role 4:

Coach

Action:

Provide feedbacks

\& Development

System:

Link Corpus (D1,

D2) to $\mathrm{C}$

Tool:

Classification

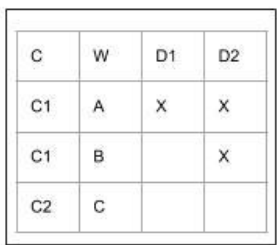

\section{Methodology}

In this section, we illustrate the chosen methodology to answer our research question. We position our study in the field of design science research (Von Alan et al., 2004) and we developed an artefact under the shape of a method, as defined by (March \& Smith, 1995), by following the process suggested by (Peffers, Tuunanen, Rothenberger, \& Chatterjee, 2007):

(1) Problem identification: as stated in section 1, we did not find in the existing literature a set of design guidelines to manage data to document experiential learning during cognitive apprenticeship.

(2) Define objective of a Solution: We wanted to develop a system that would allow the creation of a dictionary, perform text mining and automatic clustering of students' scores

(3) Design and development: We have designed a process to manage data collected during the four steps of the experiential learning cycle, as shown in figure 2.

(4) Demonstration: We have used RStudio to develop a simple system, which uses R statistical language (R. Core Team, 2013) and the library for natural language processing (Wild, 2019) to automatically assess the texts submitted by a student, extracts the most relevant concepts and allows evaluators to ask questions concerning the incoherence between the claims of the students regarding his/her skills and the evidences collected in the documents that the student has submitted. Moreover, we used the library for classification using decision trees 
(Ripley, 2019) to predict the final scores of students based on formative assessment during the semester.

(5) Evaluation: The software has been tested in 2 separate contexts. The text mining functionalities have been tested over 15 students of the team academy, whereas the classification algorithm has been tested over 100 students of a normal class. Indeed, the number of documents produced by the students of the team academy would have been not sufficient to train the classification system.

(6) Communication: The results of the study have already been presented to practitioners and they are going to be presented to academic scholars.

\section{Test results}

At the current stage, we have used the first prototype to assess the texts submitted by a test sample of students. At the beginning of the semester, we asked to our team academy students to write reflexive papers at the end of each project they have conducted, by following the theoretical framework of (Kolb \& Fry, 1975) for reflexive learning. Unfortunately, students struggle to write reflexive papers, since they are not used to reflexive practice, and the strong tendency towards apprenticeship of the team academy does not favour the improvement of the situation. Hence, we suggested students to write reports of their projects by telling a story, in which they were the hero. Epic stories are usually build around the 12 steps of the hero journey (Campbell, 1949) and such steps can be mapped to the model of (Kolb \& Fry, 1975).

Figure 3 illustrates the evolution of a student during 2 semesters. In the first semester, the student has mostly written about two distinct topics: (a) finance and (b) product development. In the second semester, the students have linked his notions of finance and product development, and he has started exploring a new topic concerning communication. 
Figure 3

Automatic Assessment of Documents Submitted by a Student

\section{Semester 01}

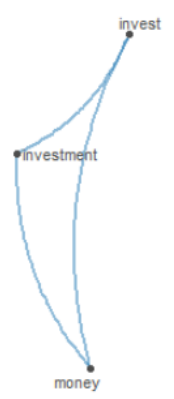

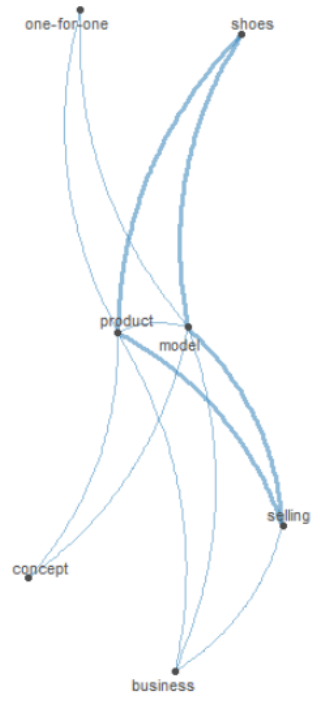

\section{Semester 02}

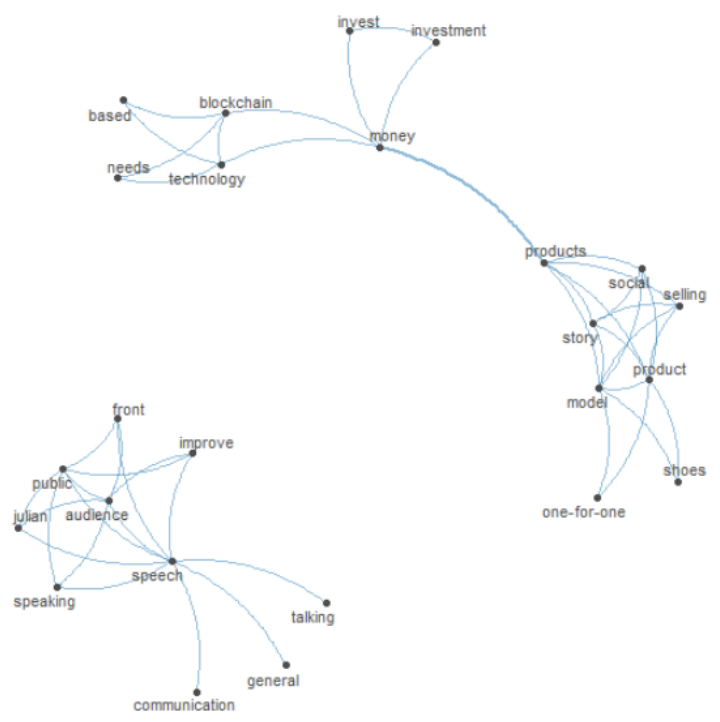

Show $2 \backsim$ entries

\begin{tabular}{|rlrrr}
\hline & Delta & \multicolumn{1}{c}{ Skills } & Semester01 & Semester02 \\
\hline 1 & 1 & $\begin{array}{l}\text { Information Processing and } \\
\text { Research Methodologies }\end{array}$ & 2 & 3 \\
2 & 1 & Team learning & 1 & 2 \\
\hline
\end{tabular}

\section{Showing 1 to 2 of 21 entries}

Source: Authors' work

The test of the second part of the artefact used data from 100 students, which have had to write a document at the end of the semester. Each week, students would receive a peer-assessment concerning the draft of their document (T1, T2, T3, .. etc), which would count as formative assessment. Then, the document would be assessed at the end of the semester (midterm) and a final test would allow assessing the performance of all students in the same testing situation.

Figure 4a shows that a simple decision tree would allow predicting the final score of each student by observing whether the student attended each class and the score of the final document. Instead, Figure $4 \mathrm{~b}$ illustrates how the formative assessment done by the peers each week can be better indicators of the final performance, suggesting that a weekly assessment would allow a more precise way to predict the final performance of each student. 
Figure 4

Automatic Assessment of Documents Submitted by a Student

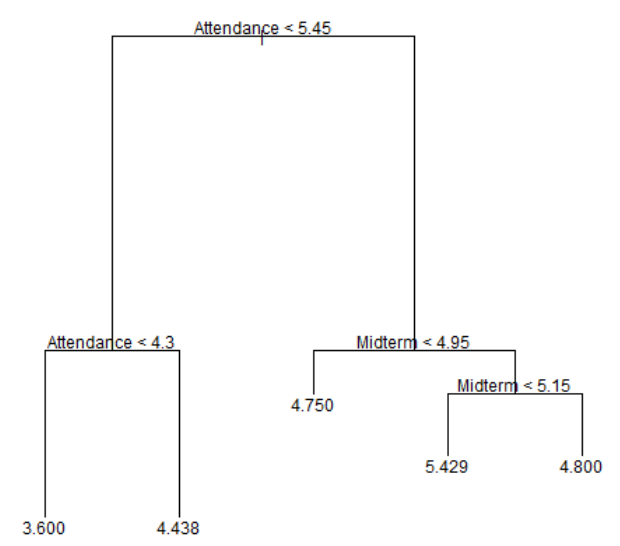

(a)

Source: Authors' work

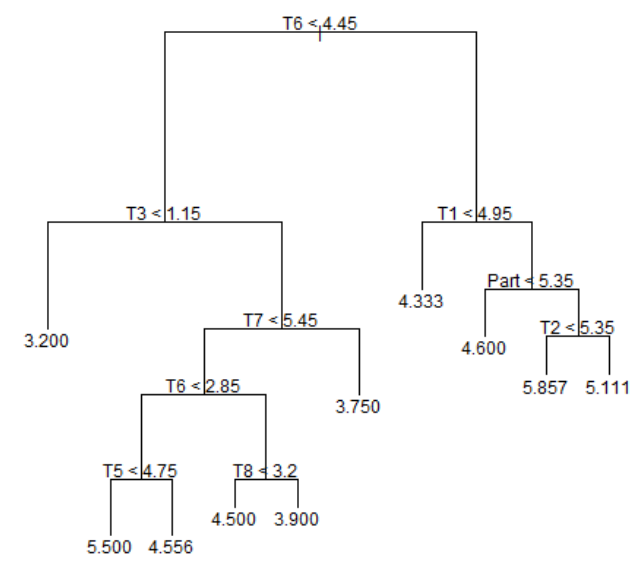

(b)

\section{Discussions and conclusions}

In this paper, we wished to understand how to support educators collect and process data in each step of the experimental learning cycle for cognitive apprenticeship. We did so by developing a system that allows educators to (1) define a set of competences, (2) link keywords to each competences, (3) analyse reflexive papers written by students as evidences of their acquired competences after practical projects and (4) analyse multiple documents to assign students to different clusters to better coach them.

The theoretical ground for our artefact can be found in the body of knowledge concerning pedagogy to define a process that would allow combining different teaching approaches and statistical learning to define the software approach to use to gather data and predict future outcomes. In doing so, we estimate having addressed a gap in the current literature.

In the current stage of development, our system had to be tested with two separate groups to obtain relevant results. Moreover, we mostly focused on performance and we did not monitor whether the system was perceived as easy to use by both educators and students. Therefore, in the future we intend to test the system again with one single group of students from the team academy, by using a larger set of performance indicators to assess the acceptance of the technology.

\section{References}

1. Campbell, J. (1949), The hero with a thousand faces, Princeton University Press, Princeton, NJ.

2. Collins, A., Brown, J. S., Newman, S. E. (1988), "Cognitive apprenticeship: Teaching the craft of reading, writing and mathematics", Thinking: The Journal of Philosophy for Children, Vol. 8, No. 1, pp. 2-10.

3. Gijbels, D., Dochy, F., Van den Bossche, P., Segers, M. (2005), "Effects of problem-based learning: A meta-analysis from the angle of assessment", Review of Educational Research, Vol. 75, No. 1, pp. 27-61.

4. James, G., Witten, D., Hastie, T., Tibshirani, R. (2013), An introduction to statistical learning, Springer. 
5. Kinchin, I. M., Hay, D. B., Adams, A. (2000), "How a qualitative approach to concept map analysis can be used to aid learning by illustrating patterns of conceptual development", Educational Research, Vol. 42, No. 1, pp. 43-57.

6. Kolb, D. A. (2014), Experiential learning: Experience as the source of learning and development, FT press.

7. Kolb, D., Fry, R. (1975), "Toward an Applied Theory of Experiential Learning", in Cooper, C. L. (Ed.), Theories of group process, John Wiley \& Sons, New York.

8. Lehtonen, T. (2010), "Introducing Jyväskylä University of Applied Science's AwardWinning Team Academy", available at:

https://learningexpedition.files.wordpress.com/2010/09/introducing_team_academy 1.pdf (27 April 2019).

9. March, S. T., Smith, G. F. (1995), "Design and Natural Science Research on Information Technology", Decision Support Systems, Vol. 15, No. 4, pp. 251-266.

10. Novak, J. D. (1990), "Concept mapping: A useful tool for science education", Journal of Research in Science Teaching, Vol. 27, No. 10, pp. 937-949.

11. Peffers, K., Tuunanen, T., Rothenberger, M. A., Chatterjee, S. (2007), "A design science research methodology for information systems research", Journal of Management Information Systems, Vol. 24, No. 3, pp. 45-77.

12. R. Core Team (2013), "R: A language and environment for statistical computing".

13. Ripley, B. (2019), "tree: Classification and Regression Trees", Version 1.0-40, available at: https://CRAN.R-project.org/package=tree (27 April 2019).

14. Tosey, P., Dhaliwal, S., Hassinen, J. (2015), "The Finnish Team Academy model: implications for management education", Management Learning, Vol. 46, No. 2, pp. 175-194.

15. Von Alan, R. H., March, S. T., Park, J., Ram, S. (2004), "Design science in information systems research", MIS quarterly, Vol. 28, No. 1, pp. 75-105.

16. Wild, F. (2019), "CRAN Task View: Natural Language Processing", available at: https://CRAN.R-project.org/view=NaturalLanguageProcessing (27 April 2019).

\section{About the authors}

Riccardo Bonazzi is professor of business model innovation at the University of Applied Science (HES-SO) of Sierre, Switzerland. He received his Ph.D. in compliance support systems from the University of Lausanne, under the supervision of Prof. Yves Pigneur and his main research interests are requirement engineering for IT governance, risk management and compliance, IT project management, decision support systems for business model innovation, and information systems for pedagogy. The author can be contacted at riccardo.bonazzi@hevs.ch.

Antoine Peruchoud, Professor at the HES-SO of Sierre, has obtained a bilingual degree in economics and social sciences at the University of Fribourg and he has completed a master's degree in the United States at Western Washington University. He is behind an innovative entrepreneurship program: "Business experience", he has been responsible for the CAS in Innovation Management since 2008, and he launched the first Team Academy in Switzerland within the HES-SO. The author can be contacted at antoine.perruchoud@hevs.ch. 